\title{
Compensation for Variable Intrinsic Neuronal Excitability by Circuit-Synaptic Interactions
}

\author{
Rachel Grashow, Ted Brookings, and Eve Marder \\ Volen Center and Biology Department, Brandeis University, Waltham, Massachusetts 02454-9110
}

Recent theoretical and experimental work indicates that neurons tune themselves to maintain target levels of excitation by modulating ion channel expression and synaptic strengths. As a result, functionally equivalent circuits can produce similar activity despite disparate underlying network and cellular properties. To experimentally test the extent to which synaptic and intrinsic conductances can produce target activity in the presence of variability in neuronal intrinsic properties, we used the dynamic clamp to create hybrid two-cell circuits built from four types of stomatogastric neurons coupled to the same model Morris-Lecar neuron by reciprocal inhibition. We measured six intrinsic properties (input resistance, minimum membrane potential, firing rate in response to $+1 \mathrm{nA}$ of injected current, slope of the frequency-current curve, spike height, and spike voltage threshold) of dorsal gastric, gastric mill, lateral pyloric, and pyloric dilator neurons from male crabs of the species Cancer borealis. The intrinsic properties varied twofold to sevenfold in each cell type. We coupled each biological neuron to the Morris-Lecar model with seven different values of inhibitory synaptic conductance and also used the dynamic clamp to add seven different values of an artificial h-conductance, thus creating 49 different circuits for each biological neuron. Despite the variability in intrinsic excitability, networks formed from each neuron produced similar circuit performance at some values of synaptic and h-conductances. This work experimentally confirms results from previous modeling studies; tuning synaptic and intrinsic conductances can yield similar circuit outputs from neurons with variable intrinsic excitability.

\section{Introduction}

Recent work has shown that similar circuit performance can be produced with highly variable sets of synaptic and intrinsic conductances (Prinz et al., 2004; Goaillard et al., 2009). Similar behavior of single neurons can also result from substantially different values of the maximal conductances of their voltagedependent currents (Goldman et al., 2001; Golowasch et al., 2002; Swensen and Bean, 2005; Achard and De Schutter, 2006; Schulz et al., 2006, 2007; Tobin and Calabrese, 2006; Sobie, 2009; Taylor et al., 2009).

Variability in the value of a given conductance across neurons of the same population is consistent with two entirely different causes. In the first instance, variability could indicate that the current in question plays only a relatively minor role in the function of the neuron, and therefore variation in its value has no appreciable influence on the neuron's firing properties. Alternatively, variability in one or more conductances might be accompanied by significant variation in other conductances that compensates for the variability to maintain constant function. For example, overexpression of the transient outward current $\left(I_{\mathrm{A}}\right)$ in lobster stomatogastric ganglion (STG) neurons produced little change in neuronal firing because it triggered compensatory changes in the hyperpolarization-activated inward current $\left(I_{\mathrm{h}}\right)$

Received Feb. 21, 2010; revised May 18, 2010; accepted May 26, 2010

This research was supported by National Institutes of Health Grants MH46742 (E.M.), F31 NS058110 (R.G.), and T32NS0792 (T.B.). We thank Adam Taylor for advice and discussions on all aspects of this work.

Correspondence should be addressed to Eve Marder, Volen Center and Biology Department, MS013, Brandeis University, 415 South Street, Waltham, MA 02454-9110. E-mail: marder@brandeis.edu.

DOI:10.1523/JNEUROSCI.0980-10.2010

Copyright $\odot 2010$ the authors $\quad 0270-6474 / 10 / 309145-12 \$ 15.00 / 0$
(MacLean et al., 2003; MacLean et al., 2005). Consistent with these data are results that show strong correlations between the expression of the mRNA encoding $I_{\mathrm{h}}$ and $I_{\mathrm{A}}$ in crab STG neurons (Schulz et al., 2006; Schulz et al., 2007; Goaillard et al., 2009).

Compensation is often invoked to explain the relative lack of phenotype in genetic deletions of many important ion channels and receptors (Swensen and Bean, 2005; Hodges et al., 2009). Compensation may be rapid (Dickman and Davis, 2009; Frank et al., 2009) or presumably may occur over longer developmental time frames (Hodges et al., 2009). In most cases where evidence for compensation exists, it is unclear how many properties are changing to control function. Even if a compensatory change is found, it is often not clear whether this change by itself is sufficient to account for the compensation of function.

In this study we first measured the variability in six intrinsic properties, each of which measures some aspect of electrical excitability in identified neurons of the same class. We then used the dynamic clamp (Sharp et al., 1993, 1996) to create hybrid two-cell networks in which every biological neuron was coupled to the same Morris-Lecar model neuron (Morris and Lecar, 1981), with artificial reciprocal inhibitory synapses and a hyperpolarization-activated inward current $\left(I_{\mathrm{h}}\right)$ added by a dynamic clamp. Using this hybrid circuit, we simulated different network configurations and saw similar outputs from disparate neurons and circuit structures. Because we varied the synaptic and $I_{\mathrm{h}}$ conductances experimentally, we were able to determine the values that allow network interactions to compensate for the variability in intrinsic properties and result in similar network outputs. This constitutes a "proof of principle" that considerable variability across a population of biological neurons is nonetheless consistent with reliable network performance. 


\section{Materials and Methods}

Male crabs (Cancer borealis) were purchased from Yankee Lobster and maintained in artificial sea water at $11^{\circ} \mathrm{C}$ until used. Crabs were placed on ice for $30 \mathrm{~min}$, after which the stomatogastric nervous system (STNS) was dissected from the stomach of the crab. The STNS was pinned to a Sylgard (Dow Corning)-coated dish and maintained in $10-12^{\circ} \mathrm{C}$ saline. Saline consisted of the following (in $\mathrm{mm}$ ): $440 \mathrm{NaCl}$, $11 \mathrm{KCl}, 13 \mathrm{CaCl}_{2}, 26 \mathrm{MgCl}_{2}, 11.2$ Trizma base, and 5 maleic acid, $\mathrm{pH} 7.45$.

Electrophysiology. The STG was desheathed and superfused with $10-12^{\circ} \mathrm{C}$ saline. Extracellular signals were recorded by placing steel pin electrodes into petroleum jelly wells surrounding select motor nerves and amplified and filtered using a differential AC amplifier (A-M Systems). Intracellular signals were recorded using 15-25 $\mathrm{M} \Omega$ glass microelectrodes filled with $20 \mathrm{~mm} \mathrm{KCl}$ and $0.6 \mathrm{M} \mathrm{K}_{2} \mathrm{SO}_{4}$ and amplified using an Axoclamp 2B amplifier (Molecular Devices). All recordings were done in discontinuous current-clamp mode with sampling rates between 1.8 and $2.1 \mathrm{kHz}$ and were acquired using a Digidata 1200 data acquisition board (Molecular Devices) using Clampex 10.2.

Dorsal gastric (DG), gastric mill (GM), lateral pyloric (LP) and pyloric dilator (PD) neurons were identified using intracellular and extracellular traces (Hooper et al., 1986; Weimann et al., 1991). To block action potential-mediated, descending neuromodulatory input, a petroleum jelly well on the desheathed stn nerve was filled with $10^{-5} \mathrm{M}$ tetrototoxin (Sigma). Picotoxin (PTX) at $10^{-5} \mathrm{M}$ (Sigma) was superfused to block glutamatergic inhibitory synapses (Marder and Eisen, 1984).

Forty minutes after the application of PTX, six intrinsic properties were measured (Fig. 1). (1) The input resistance of the neuron was measured by injecting $4 \mathrm{~s}$ of negative current from -1 to $0 \mathrm{nA}$ in steps of $0.2 \mathrm{nA}$ (Fig. $1 A$ ). The slope of the linear region of the $I-V$ curve (sampled at the steady-state voltage close to the end of the current pulse) (Fig. $1 \mathrm{~A}$, dashed line) was considered the input resistance. (2) We calculated the spike threshold voltage by injecting a ramp of current from -1 to $+1 \mathrm{nA}$ over $4 \mathrm{~s}$ (Fig. $1 B$ ). The spike threshold was the voltage at the point of maximum curvature before the first spike (curvature calculation voltage was measured in millivolts and time in milliseconds). (3) We calculated the spike height using the ramp test for the spike threshold voltage. Spike height was considered to be the voltage difference between the point of maximum curvature of the first spike and the peak voltage of that spike. (4) A frequency-current (FI) curve was measured by injecting positive current, starting from $0.0 \mathrm{nA}$ and increasing in 0.2 $\mathrm{nA}$ steps to at least $+1 \mathrm{nA}$ (Fig. 1C). Each current step was held for $5 \mathrm{~s}$ and used to calculate the slope of this curve. (5) The spike frequency elicited with the injection of $+1 \mathrm{nA}$ of current was also measured. In one cell, the spike frequency at $+1 \mathrm{nA}$ was calculated by extrapolating from the frequency-current curve because
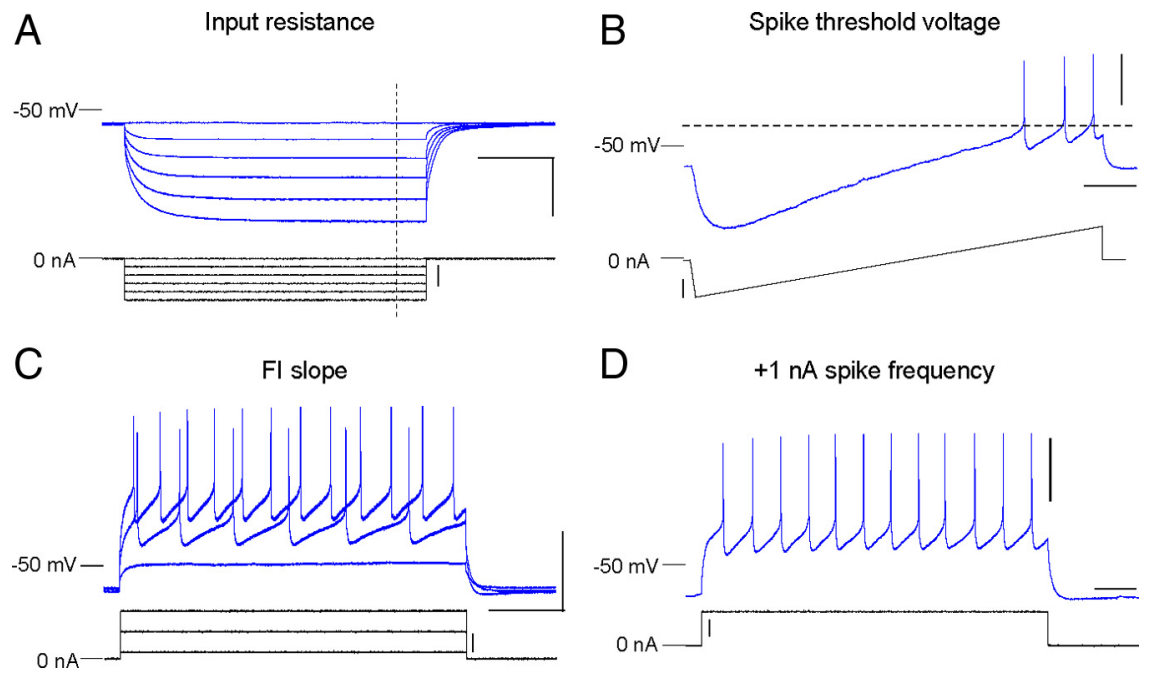

Figure 1. Four conventional measures of intrinsic neuronal excitability. In all panels the membrane potential is shown in the top traces and the injected current in the bottom traces. $A$, Input resistance is the slope of the current-voltage $(I-V)$ curve measured at the end of hyperpolarizing current steps (dotted line). $\boldsymbol{B}$, Spike threshold voltage is the voltage at the point of maximum curvature of the first spike (dotted line). $\boldsymbol{C}$, The frequency at different steps of positive current was used to calculate the slope of the Fl curve. Only three of eight voltage and current traces are shown for visualization purposes. $D$, Spike frequency measured at +1 $\mathrm{nA}$. Vertical scale bar on voltage traces, $20 \mathrm{mV}$; vertical scale bar on current traces, $0.5 \mathrm{nA}$; horizontal scale bars, $0.5 \mathrm{~s}$.
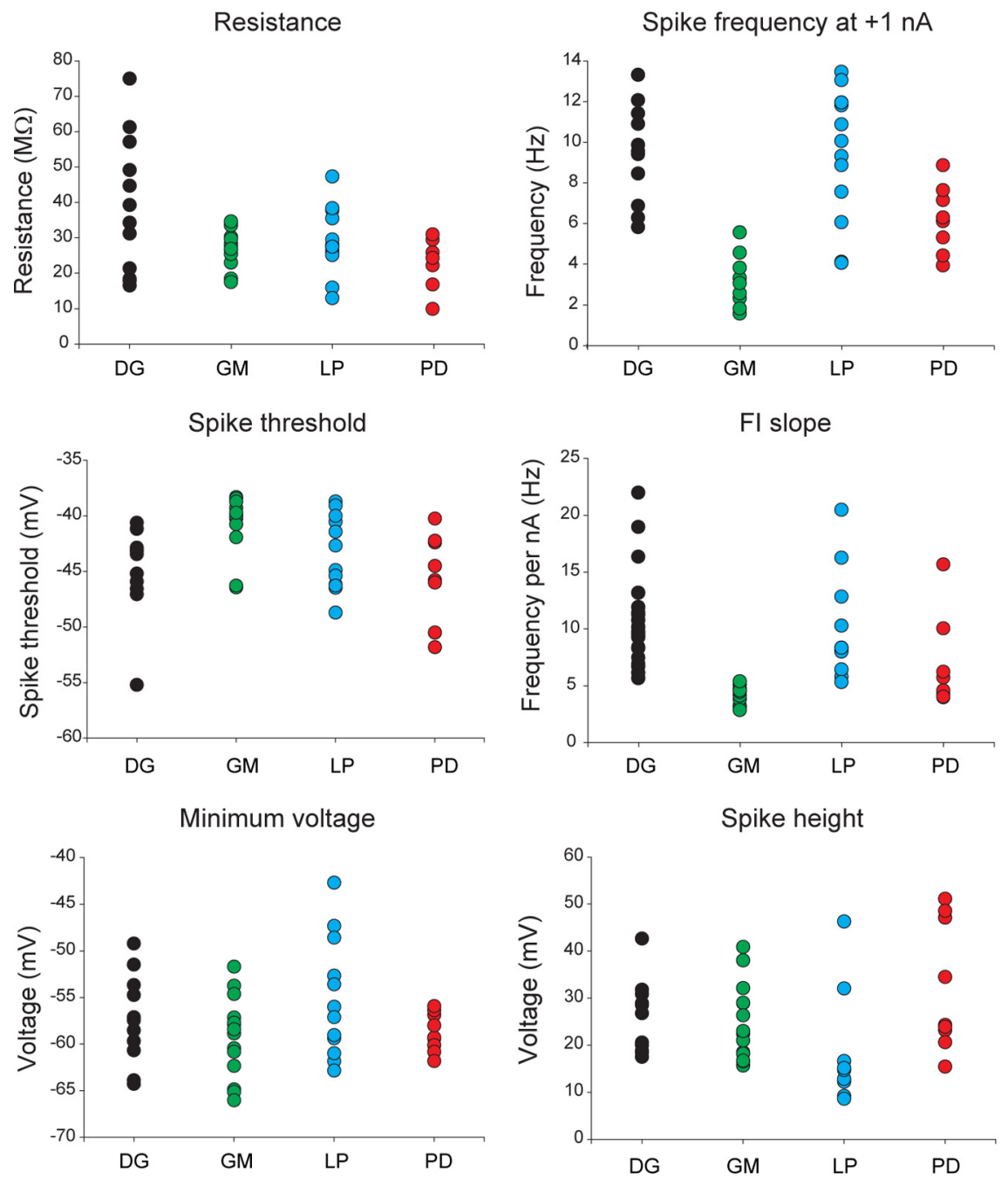

Figure 2. Variability of six conventional measures of intrinsic excitability. Measures of input resistance, spike threshold voltage, spike height, slope of the frequency-current curve, spike frequency at $+1 \mathrm{nA}$, and minimum voltage for the $D G(n=12), \mathrm{GM}$ $(n=14), \operatorname{LP}(n=12)$, and PD $(n=9)$ neurons. 
Table 1. Intrinsic property means, standard deviations, and significant mean differences between pairs of cell types

\begin{tabular}{|c|c|c|c|c|c|c|}
\hline Cell type & Input resistance $(\mathrm{M} \Omega$ ) & Spike threshold (mV) & Fl slope $(\mathrm{Hz} / \mathrm{nA})$ & Spike frequency at $+1 \mathrm{nA}(\mathrm{Hz})$ & $\begin{array}{l}\text { Minimum resting } \\
\text { voltage }(\mathrm{mV})\end{array}$ & $\begin{array}{l}\text { Spike height } \\
\text { (mV) }\end{array}$ \\
\hline DG & $39.0 \pm 19.1$ (*PD) & $-44.6 \pm 4.0\left({ }^{*} \mathrm{LP}\right)$ & $11.8 \pm 4.7\left({ }^{* * *} \mathrm{GM}\right)\left({ }^{*} \mathrm{PD}\right)$ & $9.6 \pm 2.4\left({ }^{* * *} \mathrm{GM}\right)\left({ }^{*} \mathrm{PD}\right)$ & $-57.3 \pm 4.6$ & $25.4 \pm 7.5$ \\
\hline GM & $27.5 \pm 5.2$ & $-40.6 \pm 2.6(* * \mathrm{LP})$ & $4.3 \pm 0.8(* * * D G)(* * \mathrm{LP})$ & $3.0 \pm 1.14\left({ }^{* *} \mathrm{DG}\right)\left({ }^{* * *} \mathrm{LP}\right)\left({ }^{* *} \mathrm{PD}\right)$ & $-59.3 \pm 4.3$ & $24.8 \pm 8.1$ \\
\hline $\mathrm{LP}$ & $29.3 \pm 9.6$ & $-43.3 \pm 3.4\left({ }^{*} \mathrm{DG}\right)\left({ }^{* *} \mathrm{GM}\right)$ & $9.8 \pm 4.6\left({ }^{* *} \mathrm{GM}\right)$ & $9.2 \pm 3.2(* * * \mathrm{GM})\left({ }^{*} \mathrm{PD}\right)$ & $-55.2 \pm 6.4$ & $17.2 \pm 11.0(* * P D)$ \\
\hline PD & $24.3 \pm 5.6\left({ }^{*} \mathrm{DG}\right)$ & $-46.0 \pm 4.1$ & $6.5 \pm 4.0\left({ }^{*} \mathrm{DG}\right)$ & $6.4 \pm 1.5\left({ }^{*} \mathrm{LP}\right)\left({ }^{* *} \mathrm{GM}\right)\left({ }^{*} \mathrm{DG}\right)$ & $-58.7 \pm 2.1$ & $32.1 \pm 13.6\left({ }^{* *} \mathrm{LP}\right)$ \\
\hline
\end{tabular}

Each row shows a cell type that demonstrated a significantly different mean as measured by a one-way ANOVA; asterisks represent $p$ values $\left({ }^{*} p<0.05\right.$; ${ }^{* *} p<0.01$; $\left.{ }^{* * *} p<0.001\right)$. For input resistance, PD and GM were significantly different $(p=0.028)$. DG and $\mathrm{LP}(p=0.038)$ and $\mathrm{GM}$ and $\mathrm{LP}(p=0.001)$ showed significantly different spike threshold values. For FI slope, $\mathrm{DG}$ and $\mathrm{GM}(p<0.001), \mathrm{GM}$ and $\mathrm{LP}(p=0.004)$, and $\mathrm{DG}$ and $\mathrm{PD}(p=0.014)$ were statistically different from one another. For spike frequency at $+1 \mathrm{nA}, \mathrm{DG}$ and GM $(p<0.001)$, GM and $\mathrm{LP}(p<0.001), \mathrm{LP}$ and PD $(p=0.031), \mathrm{DG}$ and $\mathrm{PD}(p=0.011)$, and $\mathrm{GM}$ and $\mathrm{PD}(p=0.005)$ showed statistically significant mean values. No significant differences between means were found in minimum voltage measurements. PD and LP showed statistically significant differences in mean spike height $(p=0.008)$.

the maximum current injection was below $+1 \mathrm{nA}$. (6) The minimum voltage was taken from the FI curve at $0 \mathrm{nA}$ of injected current (data not shown). For silent neurons, this was the resting potential. For active neurons, this was the most hyperpolarized membrane potential reached over the $5 \mathrm{~s}$ step.

Dynamic clamp. Real-time Linux dynamic clamp (Dorval et al., 2001), version 2.6, was run on an $800 \mathrm{MHz}$ Dell Precision desktop computer. All dynamic-clamp recordings were done in discontinuous current-clamp mode with sampling rates between 1.8 and $2.1 \mathrm{kHz}$. A Morris-Lecar (Morris and Lecar, 1981) model neuron was simulated using the dynamic clamp. This model contained a noninactivating $\mathrm{Ca}^{2+}$ conductance and a noninactivating $\mathrm{K}^{+}$conductance, in addition to a leak conductance. The membrane voltage of the MorrisLecar neuron was determined based on the following equations:

$$
\begin{gathered}
C \frac{d V}{d t}=-\bar{g}_{\text {leak }}\left(V-E_{\text {leak }}\right)-\bar{g}_{\mathrm{Ca}} M\left(V-E_{\mathrm{Ca}}\right)-\bar{g}_{\mathrm{K}} N\left(V-E_{\mathrm{K}}\right) \\
\frac{d N}{d t}=\tau_{\mathrm{N}}\left(N_{\infty}-N\right) \\
\frac{d M}{d t}=\tau_{\mathrm{M}}\left(M_{\infty}-M\right) \\
M_{\infty}=\frac{1+\exp \left(\frac{-\left(V-V_{1 / 2, \mathrm{Ca}}\right)}{V_{\text {slope } \mathrm{Ca}}}\right)}{1} \\
N_{\infty}=\frac{1+\exp \left(\frac{-\left(V-V_{1 / 2, \mathrm{~K}}\right)}{V_{\text {slope } \mathrm{K}}}\right)}{\tau_{\mathrm{N}}}=\tau_{0 \mathrm{~K}} \operatorname{sech}\left(\frac{V-V_{1 / 2, \mathrm{~K}}}{2 V_{\text {slope } \mathrm{K}}}\right)
\end{gathered}
$$

The membrane capacitance of the Morris-Lecar model neuron, $C$, was $10 \mathrm{nF} \cdot \bar{g}_{\mathrm{Ca}}(200 \mathrm{nS}), \bar{g}_{\mathrm{K}}(200 \mathrm{nS})$, and $\bar{g}_{\text {leak }}(50 \mathrm{nS})$ are the maximal conductances for the $\mathrm{Ca}^{2+}, \mathrm{K}^{+}$, and leak conductances, respectively. $V_{1 / 2 \text {, Ca }}(-20 \mathrm{mV})$ is the half-activation voltage of the $\mathrm{Ca}^{2+}$ conductance, and $V_{\text {slope,Ca }}(15 \mathrm{mV})$ is the slope of the activation curve for $\mathrm{gCa}^{2+} \cdot E_{\mathrm{Ca}}(100 \mathrm{mV})$ is the reversal potential for the $\mathrm{Ca}^{2+}$ current, and $\tau_{\mathrm{M}}(1 \mu \mathrm{s})$ is the time constant for the activation variable $M$ of the $\mathrm{Ca}^{2+}$ conductance. $V_{1 / 2, \mathrm{~K}}(-20 \mathrm{mV})$ is the half-activation of the $\mathrm{K}^{+}$ current, $V_{\text {slope, } \mathrm{K}}(15 \mathrm{mV})$ is the slope of the activation curve for the $\mathrm{K}^{+}$conductance, and $E_{\mathrm{K}}(-80 \mathrm{mV})$ is the reversal potential of $\mathrm{K}^{+} . \tau_{0 \mathrm{~K}}$ $(500 \mathrm{~ms})$ is the scale factor for the time constant for the activation variable $N$ of the $\mathrm{K}^{+}$current. $E_{\text {leak }}(-60 \mathrm{mV})$ is the reversal potential for the leak current.

An artificial hyperpolarization-activated conductance, $I_{\mathrm{h}}$ (Buchholtz et al., 1992; Sharp et al., 1996), was added to the STG neuron using the dynamic clamp and is described by the following equations:

$$
\begin{aligned}
& I_{\mathrm{h}}=\bar{g}_{\mathrm{h}} R\left(E_{\mathrm{h}}-V\right) \\
& \frac{d R}{d t}=k_{\mathrm{R}}\left(R_{\infty}-R\right)
\end{aligned}
$$

where

$$
\begin{gathered}
R_{\infty}(V)=\frac{1}{1+\exp \left[\left(V-V_{1 / 2}\right) / s_{\mathrm{R}}\right]} \\
k_{\mathrm{R}}(V)=c_{\mathrm{R}}\left\{1+\exp \left[\left(V-V_{\mathrm{kR}}\right) / s_{\mathrm{kR}}\right]\right\},
\end{gathered}
$$

where $\bar{g}_{\mathrm{h}}$ (varied from 10 to $100 \mathrm{nS}$ ) is the maximal $g_{\mathrm{h}}, R$ is the instantaneous activation, $R_{\infty}$ is the steady-state activation, $E_{\mathrm{h}}(-10 \mathrm{mV})$ is the $g_{\mathrm{h}}$ reversal potential, $V_{1 / 2}(-50 \mathrm{mV})$ is the half-maximum activation, $s_{\mathrm{R}}(7$ $\mathrm{mV})$ is the step width, $c_{\mathrm{R}}(0.33 / \mathrm{s})$ is the rate constant, $V_{\mathrm{kR}}(-110 \mathrm{mV})$ is the half-maximum potential for the rate, and $s_{\mathrm{kR}}(-13 \mathrm{mV})$ is the step width for the rate.

The dynamic clamp was used to simulate an inhibitory synapse from the model neuron to the biological neuron ( $g_{\text {synML }}$; varied from 10 to 100 $\mathrm{nS}$ ) as well as a synapse from the biological cell to the model neuron ( $g_{\text {synbio }}$; varied from 20 to $200 \mathrm{nS}$ ). Before experimentation, both model and synaptic parameters were chosen to configure a circuit that dynamically interacted with each type of biological neuron. All model and circuit parameters were identical in each experiment. The maximal conductance of $g_{\text {synbio }}$ was twice as large as that of $g_{\text {synML }}$ for all map points. These artificial inhibitory graded transmission synapses were based on Sharp et al. (1996) and are described by the following equations:

$$
\begin{gathered}
I_{\text {syn }}=\bar{g}_{\text {syn }} \cdot S \cdot\left(E_{\text {syn }}-V_{\text {post }}\right) \\
\left(1-S_{\infty}\right) \tau_{\text {syn }} \frac{d S}{d t}=\left(S_{\infty}-S\right)
\end{gathered}
$$

where

$$
S_{\infty}\left(V_{\text {pre }}\right)=\left\{\begin{array}{cl}
\tanh \left[\left(V_{\text {pre }}-V_{1 / 2}\right) / V_{\text {slope }}\right] & \text { if } V_{\text {pre }}>V_{1 / 2} \\
0 & \text { otherwise }
\end{array}\right\},
$$

where $\bar{g}_{\text {syn }}$ is the maximal synaptic conductance, $S$ is the instantaneous synaptic activation, $S_{\infty}$ is the steady-state synaptic activation, and $E_{\text {syn }}(-70 \mathrm{mV}$ for Morris-Lecar and $-80 \mathrm{mV}$ for biological neuron) is the reversal potential of the synaptic current. $V_{\text {pre }}$ and $V_{\text {post }}$ are the presynaptic and postsynaptic potentials, respectively; $\tau_{\text {syn }}(100$ $\mathrm{ms})$ is the time constant for synaptic decay, $V_{1 / 2}(-45 \mathrm{mV})$ is the synaptic half-activation voltage, and $V_{\text {slope }}(5 \mathrm{mV})$ is the synaptic slope voltage.

Parameter maps. First, the output of the model neuron and the STG neuron was recorded in an uncoupled state $\left(\bar{g}_{\text {synML }}, \bar{g}_{\text {synbio }}=0 ; \bar{g}_{\mathrm{h}}=0\right)$. Then, the maximal artificial h-conductance in the STG neuron $\left(\bar{g}_{\mathrm{h}}\right)$ and the maximal model to biological synaptic conductance $\left(\bar{g}_{\text {synML }}\right)$ were varied from 10 to $100 \mathrm{nS}$ in $15 \mathrm{nS}$ steps, with the biological to model synapse $\left(\bar{g}_{\text {synbio }}\right)$ always being twice the value of $\bar{g}_{\text {synML }}$. The parameter sets were sampled in a random order. A sample of the circuit output was recorded at every $g_{\text {syn }}$ and $g_{\mathrm{h}}$ parameter combination. We classified network activity into four categories: (1) networks that were silent, (2) those dominated by the model, (3) those dominated by the STG neuron, or (4) those that formed half-center oscillators in which the biological and model neurons were active in antiphase (see below for network classifi- 
cation algorithm description). All non-half-center networks were recorded for $30 \mathrm{~s}$. When the network was half-center or when the network fluctuated between different network categories, samples from 90 to $180 \mathrm{~s}$ were recorded.

Spike detection. Data were imported to Matlab and then analyzed using custom scripts. Spikes were automatically identified from an analysis of the "phase plot," $d V / d t$ ( $y$-axis) versus $V$ ( $x$-axis). To decrease the impact of variability in the slow wave, $V$ was high-pass filtered with a time constant of $30 \mathrm{~ms}$, but $d V / d t$ was left unchanged. Data with spikes yield distinct clockwise loops with few data points in the interior of the loops, whereas data without spikes yield points scattered throughout a roughly circular region. To detect spikes, we defined a point in the interior of the plot as a "central" point. The $y$-coordinate of this point, $(d V / d t)_{\text {central }}$, was half the maximum value obtained by $d \mathrm{~V} / d t$. The $x$-coordinate of the central point, $V_{\text {central }}$, was the voltage at the time of maximum $d V / d t$. Putative spikes were identified as trajectories that began and ended with $V=V_{\text {central }}$, and looped clockwise around the interior point (specifically, they had $d V / d t>(d V / d t)_{\text {central }}$ before $\left.V>V_{\text {central }}\right)$. The spike time was recorded as the time of peak voltage. To distinguish true spikes from the random fluctuations of a silent cell, a count was made of the number of time samples with high voltage $\left(V>V_{\text {central }}\right)$ but low $d V / d t[d V / d t<$ $\left.(d V / d t)_{\text {central }}\right]$. If this number was $>20 \%$ of the number of putative spikes, the data were classified as nonspiking, and all putative spikes were ignored. In practice, we found this to be nearly perfect at identifying spikes and distinguishing spiking from nonspiking traces.

Slow-wave detection. Here, we use "slow wave" to refer to any lowfrequency membrane oscillations. We identified slow-wave oscillations by removing spikes via interpolation and low-pass filtering the resulting waveform. We then found the highest-frequency peak in the autocorrelogram below the spike frequency. We looked for local (over a time period proportional to slow-wave frequency) maximums and minimums in the resulting waveform, these being putative peaks and troughs of the slow wave. Peaks/troughs were deemed to be spurious if they were excessively hyperpolarized/depolarized compared with the others, using a three $\sigma$ cutoff. Such extrema were removed, along with one of their neighbors (e.g., a spurious peak would be removed along with the most depolarized adjacent trough). The level of ongoing high-frequency noise was determined by high-pass filtering the waveform. If the median slowwave amplitude was less than the amplitude of the smallest $95 \%$ of noise, then the cell was deemed to have no slow wave. Finally, slow waves were removed if they were plausibly fluctuations in the aftermath of a spike. Specifically, if an individual slow wave had an amplitude less than the difference between the prespike voltage and postspike voltage of the most recent spike, it was deemed spurious.

Burst detection. Putative bursts were identified as depolarizing deflections of the biological cell's membrane potential, which occurred during a slow-wave peak. If the majority of putative bursts did not have spikes, the system was deemed to have no bursts. Otherwise the bursts were expanded as necessary to ensure that all in-burst spikes were fully included in the burst period. Finally, if the gap between two bursts was less than a typical interspike interval, the two bursts were merged into one large burst.

The burst waveforms from the four different cell types were sufficiently variable so that occasionally the automated analysis misidentified bursts. Therefore, we visually checked identified bursts and manually modified the results of erroneous automatic calculations.

Network classification and measurement. Networks were classified as "silent," "model dominated," "bio dominated," or "half-center." If the biological cell's activity lacked spikes and a slow wave, it was categorized as "silent." If the biological cell showed spikes but no slow wave, the network was labeled "bio dominated." If a slow wave but no spikes were present in the biological cell, the network was labeled "model dominated". To determine whether the system was halfcenter, we examined the synaptic current between the Morris-Lecar model and the biological cell. We counted the fraction of times the inhibitory synaptic current was predominantly from the bursting cell (the biological and the model cell in turn) to the nonbursting cell. If this number was $>90 \%$, the network was "half-center"; otherwise, it was "bio dominated."
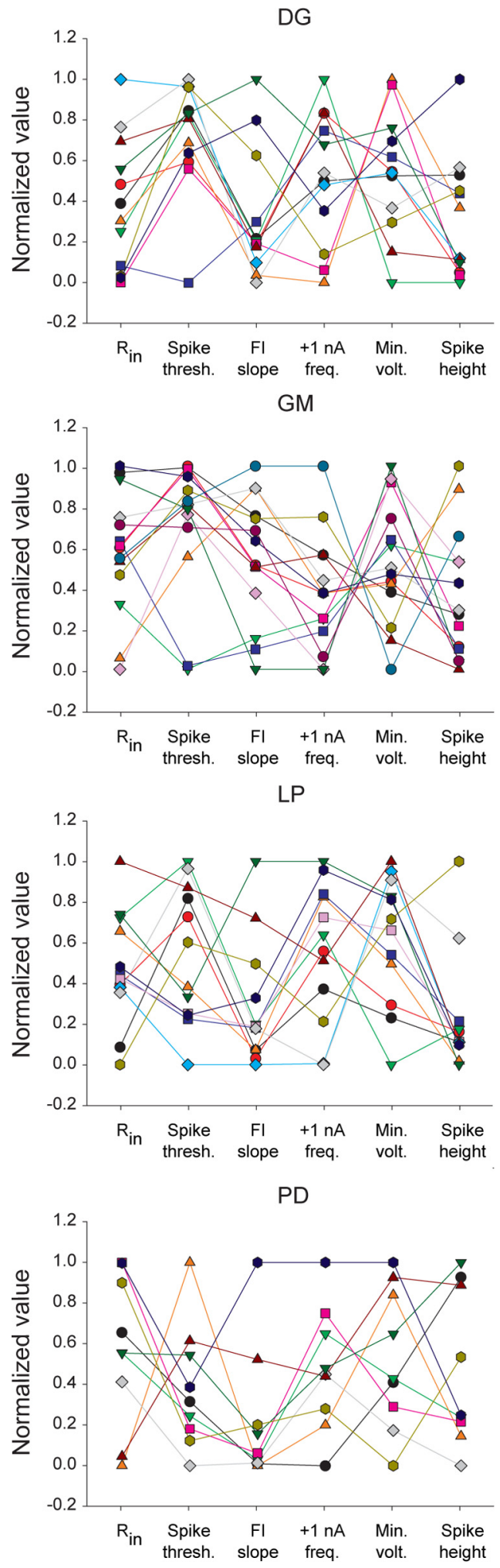

Figure 3. Normalized values for intrinsic properties grouped by cell type. Each unique symbol represents one neuron; lines connect the intrinsic property measurements for individual neurons. $R_{\text {in }}$ Input resistance; freq., frequency; min. volt., minimum voltage.

The network frequency was measured for every half-center network in addition to the burst duration, duty cycle, spike frequency within each burst, and the number of spikes per burst in the biological neuron. To determine the regularity of each half-center network we calculated the autocorrelation for the neuron's membrane potential (an autocorrela- 
A

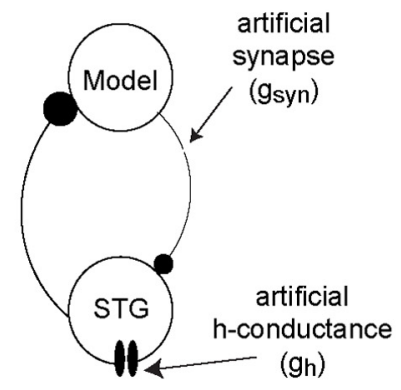

$\mathrm{B}$

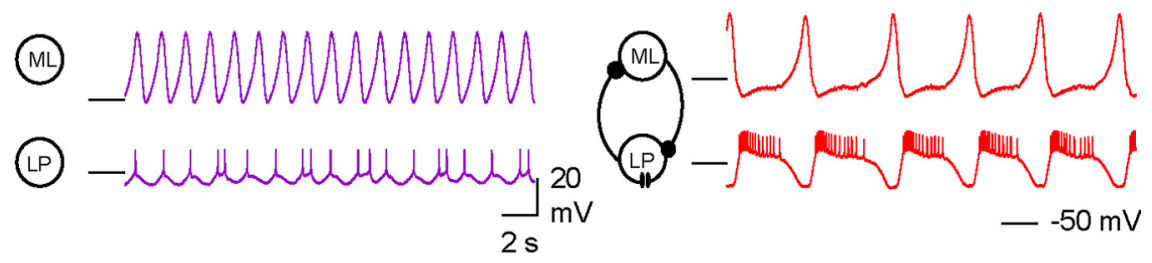

$\mathrm{F}$
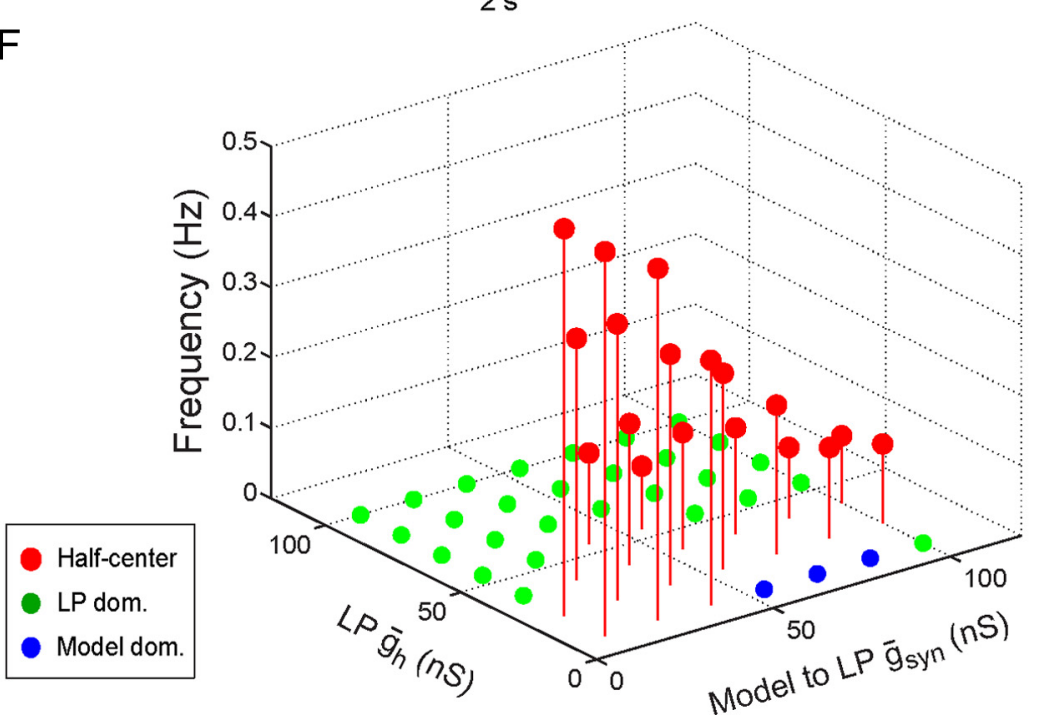

Figure 4. Network output of the hybrid circuit depends on $g_{\text {syn }}$ and $g_{\mathrm{h}}$ parameter values. $\boldsymbol{A}$, Circuit schematic for a two-cell network built with a model Morris-Lecar neuron coupled to a biological STG neuron (either DG, GM, LP, or PD). The dynamic clamp was used to simulate artificial asymmetrical inhibitory synapses and an artificial $\mathrm{h}$-conductance that was added to the STG neuron. $B$, Voltage traces from an uncoupled ( $g_{\text {syn }}=0 \mathrm{nS}, g_{\mathrm{h}}=0 \mathrm{nS}$ ) endogenously active Morris-Lecar model neuron (top) and LP neuron (bottom trace). $\boldsymbol{C}-\boldsymbol{E}$, Voltage traces from different $g_{\mathrm{syn}}-g_{\mathrm{h}}$ parameter value combinations. Colors delineate network category: red traces indicate half-center networks, blue represents networks dominated by the model neuron, and green traces indicate networks dominated by the LP neuron. C, $g_{\text {syn }}=85 \mathrm{nS}, g_{\mathrm{h}}=70 \mathrm{nS}$. D, $g_{\text {syn }}=70 \mathrm{nS}, g_{\mathrm{h}}=10 \mathrm{nS} . \mathbf{E}, g_{\text {syn }}=40 \mathrm{nS}, g_{\mathrm{h}}=$ $40 \mathrm{nS}$. $F$, Map of network types within the $g_{\text {synn }}-g_{\mathrm{h}}$ parameter space for the $L P$ to model hybrid circuit. Network frequency is shown on the $z$-axis for only the half-center networks.

tion of 0 corresponds to completely irregular; 1 corresponds to perfect regularity).

\section{Results}

The crab STG contains approximately 26 neurons (Kilman and Marder, 1996), which can be unambiguously identified by their anatomical projections and synaptic connections. The STG generates two different motor patterns, the fast pyloric rhythm and the slower gastric mill rhythm. Each neuronal type displays characteristic electrophysiological discharge patterns when these rhythms are active (Marder and Bucher, 2007). There are two PD neurons and one LP neuron in each STG, and these neurons are rhythmically active in the ongoing pyloric rhythm. There is one DG neuron and approximately four GM neurons in each STG. These neurons are part of the episodic gastric mill rhythm (Selverston et al., 1976; Clemens et al., 1998; Nusbaum and Beenhakker, 2002).

\section{Intrinsic property measurements of identified cell types}

Over the years a number of studies have characterized the biophysical properties of specific membrane conductances in crab STG neurons, most notably in the LP and DG neurons (Golowasch et al., 1992, 1999b; Kiehn and Harris-Warrick, 1992a,b; Zhang and Harris-Warrick, 1995; Zhang et al., 1995; Schulz et al., 2006). Nonetheless, there have been no direct comparisons of the intrinsic properties of different classes of STG neurons using many of the direct measures most often found in the literature. Consequently, we first pharmacologically isolated DG, GM, LP, and PD neurons and then measured the input resistance, action potential voltage threshold, spike height, slope of the FI curve, the spike frequency with $+1 \mathrm{nA}$ injected current, and minimum voltage (Fig. 1). As an aggregate, these intrinsic properties are measures of the attributes that contribute to neuronal excitability.

Figure 2 shows that while each cell type shows a considerable spread in the values of each measure, almost all of these measurements overlapped across the cell types, although the values for the GM neurons showed somewhat less dispersal than did the other neuron types. Table 1 shows the means and standard deviations of these intrinsic properties for each cell type. Despite the extensive overlap, all of the intrinsic properties except for the minimum membrane potential showed some statistically different values across cell types (Table 1).

Figure 3 shows normalized intrinsic property values organized by cell type, with lines connecting the intrinsic properties of each individual cell. The many line crossings illustrate the lack of relationships between the different intrinsic properties. Despite the overlap in intrinsic property measurements and the inconsistency of the rank-ordered measurements, we wanted to know whether any of the intrinsic property measurements within each cell type showed any correlation.

GM showed a significant correlation between the spike threshold voltage and $+1 \mathrm{nA}$ spike frequency measurements $\left(R^{2}=0.85\right.$, $p<0.001$, all $p$ values adjusted by Bonferroni correction), the spike threshold voltage and the minimum voltage $\left(R^{2}=0.95\right.$, $p<0.001)$, and the minimum voltage and the $+1 \mathrm{nA}$ spike frequency $\left(R^{2}=0.85, p<0.001\right)$. No significant pairwise correlations were found for the other cell types. We asked whether a linear combination of any five properties predict the sixth, and found no additional relationships (data not shown). 
Using hybrid model/biological networks to assess the functional consequence of cell variability

To determine whether we could get similar outputs from cells with variable intrinsic properties, we used the dynamic clamp (Sharp et al., 1993) to create hybrid model/ biological neuron circuits (Sorensen et al., 2004; Olypher et al., 2006). Specifically, we connected biological PD, LP, GM, and DG neurons to a model Morris-Lecar neuron (Morris and Lecar, 1981) via reciprocally inhibitory synapses $\left(g_{\text {syn }}\right)$ (Fig. $4 A$, schematic). We also added an artificial excitatory h-conductance $\left(g_{\mathrm{h}}\right)$ (Buchholtz et al., 1992; Sharp et al., 1996) to the biological cell to determine whether changes in the strengths of synaptic and intrinsic membrane currents could compensate for diverse intrinsic excitability to produce equivalent outputs.

Figure $4 B$ shows an LP neuron and the model neuron when uncoupled. The Morris-Lecar model endogenously oscillated at $0.67 \mathrm{~Hz}$, while the LP neuron fired tonically. Figure $4 C$ shows voltage traces recorded after the LP neuron was coupled to the Morris-Lecar neuron at different $g_{\text {syn }}{ }^{-} g_{\mathrm{h}}$ parameter value combinations. The activity of the hybrid circuit was categorized into four classes: (1) circuits in which the model inhibited the LP neuron ("model dominated"; blue), (2) circuits with the biological neuron inhibiting the model ("LP dominated"; green), (3) circuits where both neurons were silent (data not shown), and (4) circuits that showed alternating half-center activity (red). A map of how the activity of the circuit depended on the $g_{\text {syn }}$ and $g_{\mathrm{h}}$ values is shown in Figure $4 F$, with the burst frequency of the halfcenters shown on the $z$-axis. All of the $g_{\text {syn }}$ map axes in the figures represent only the model to biological synapse, but the biological to model synapse was varied proportionately (see Materials and Methods).

We performed 12 LP neuron experiments, each with 49 unique networks ( 7 values were used for both $g_{\text {syn }}$ and $g_{\mathrm{h}}$, and all possible combinations were sampled). In every experiment there were a number of $g_{\text {syn }}$ and $g_{\mathrm{h}}$ values that commonly produced half-center oscillators. Figure $5 A$ shows the distribution of all LP to model half-center circuits from these 12 experiments, with the percentage of half-center networks at each location represented as a color-intensity-coded value between 0 and $100 \%$. Note that there were no half-center oscillators formed from LP neurons at the higher values of $g_{\mathrm{h}}$, and all the preparations produced halfcenter activity at $g_{\mathrm{h}}=20 \mathrm{nS}$, and most at $g_{\mathrm{h}}=40 \mathrm{nS}$.

\section{Compensating for neuronal variability to produce consistent target network performance}

The fact that all preparations produced half-center oscillations at similar areas in the parameter maps raised the question of whether each neuron could, at some set of map parameters, be part of a two-cell network with a defined output. To ask this question, for each neuron type we looked for a specific "target" network perfor-

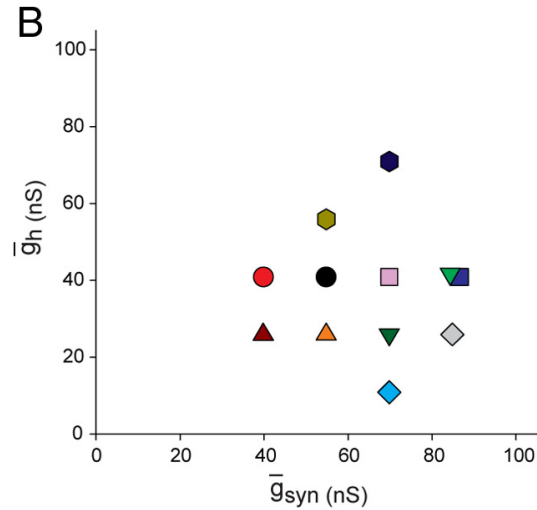

LP \#2
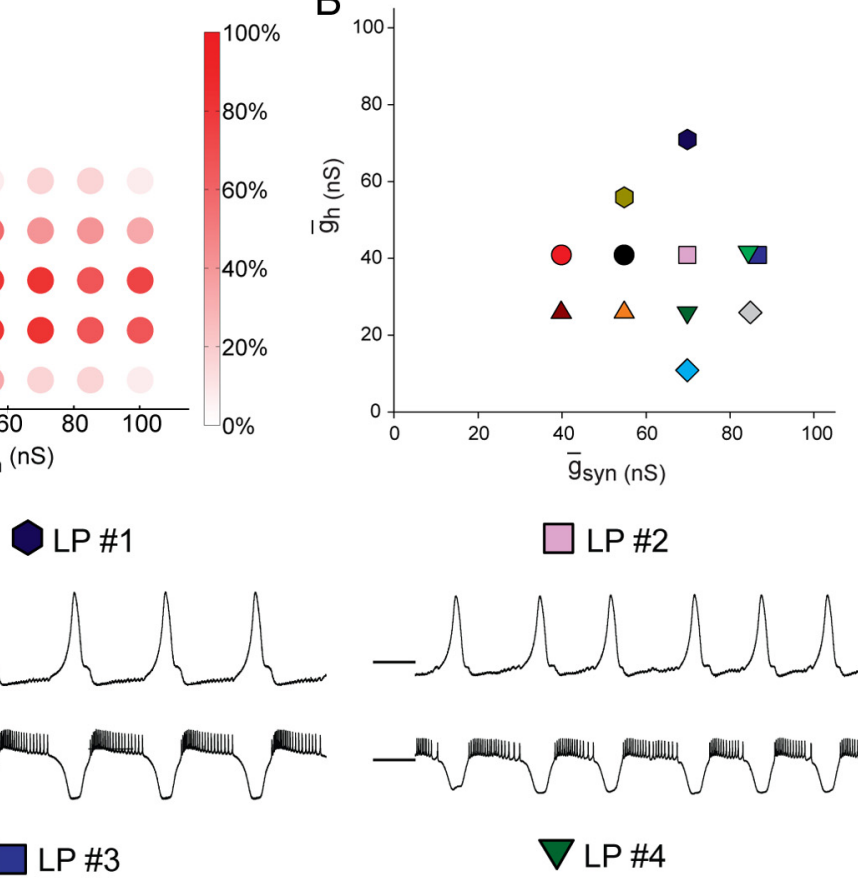

$\square$ LP\#3

$\nabla$ LP\#4

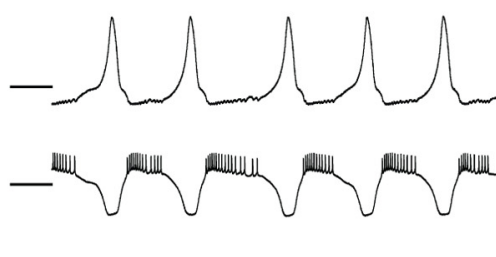

20

a Morris-Lecar model neuron at different $g_{\text {syn }}-g_{\mathrm{h}}$ values. $\boldsymbol{A}$, Pooled distribution of LP-model half-center circuits for $12 \mathrm{LP}$ neurons. Red scale indicates fraction of half-centers at each $g_{\text {syn }}-g_{\mathrm{h}}$ parameter combination. $\boldsymbol{B}, g_{\text {syn }}-g_{\mathrm{h}}$ parameter values for each LP neuron that produced similar LP-model half-center networks. $\boldsymbol{C}$, Six LP-model half-center networks with similar behavior (see Results). Symbols correspond to Figures 3 and $5 B$.

mance and then determined whether this target performance was achievable in every individual neuron of that cell type. For each cell the target was chosen after looking for the prevalent circuit dynamics that were present in the data from all of the individual cells of that type. Using this as a starting point, we formulated strict criteria and found all examples of networks that met those criteria.

For the LP neuron, the target activity was a frequency range of $0.15-0.30 \mathrm{~Hz}$, a duty cycle $>0.65$, and an autocorrelation score of $>0.27$. There were 48 networks found in the 12 experiments that fell within this general range of behaviors. From these, we selected by eye a representative network from each experiment with a similar target waveform. Figure $5 C$ shows voltage traces for 4 of the 12 LP experiments. Symbols above each trace correspond to cell identifiers in Figures 3 and $5 B$. Figure $5 B$ shows the $g_{\text {syn }}$ and $g_{\mathrm{h}}$ values that produced these similar outputs from LP neurons despite their variable intrinsic properties. Note that there is a sevenfold variability in the $g_{\mathrm{h}}$ values and a more than twofold variability in the $g_{\text {syn }}$ values that produced the representative network performance, a magnitude that is equivalent to the variability measured in biological networks (Prinz et al., 2004; Schulz et al., 2006, 2007; Goaillard et al., 2009).

\section{Maps from different cell types}

Despite the large spread of the intrinsic properties measurements, Table 1 showed that on average there were significant differences between some of these measurements across cell 

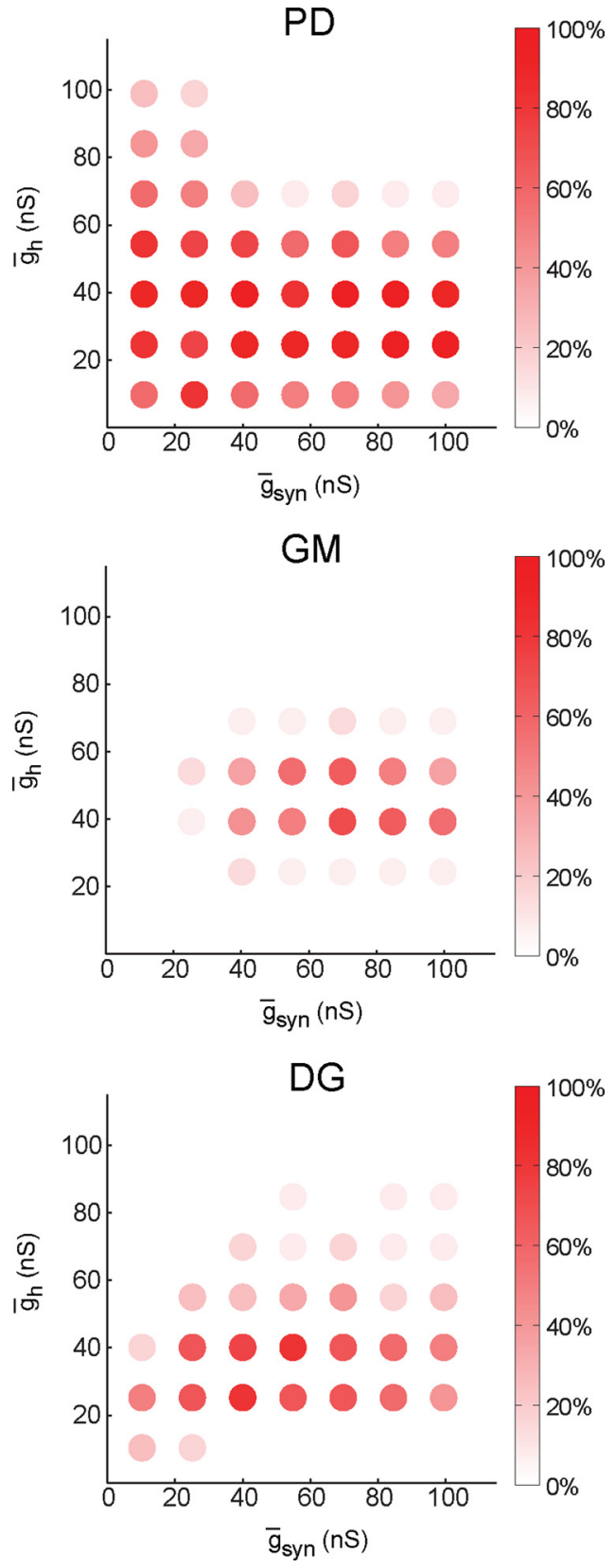

Figure 6. Distribution of half-center networks for all PD, GM, and DG model networks. Red scale corresponds to percentage of half-centers at each $g_{\text {syn }}-g_{\mathrm{h}}$ parameter combination.

types. This suggests that when neurons of these different cell types are coupled to the same Morris-Lecar model neurons, the maps formed would also be different. Visual comparisons of the maps in Figures $5 A$ and 6 show that the distribution of half-center networks appears to be cell type specific. For example, the PD neuron pooled map is much larger than those of the other cell types, and the GM map pooled map is much smaller (Fig. 6). A one-way ANOVA revealed that the percentages of the map with half-center networks were significantly different $(p<0.001)$, and post hoc Tukey tests revealed that all pairs of the cells were also significantly different. Nonetheless, it is important to stress that these pooled maps also show that all four cell types produced half-center oscillators at some common parameter regions (e.g., $\left.g_{\text {syn }}=70 \mathrm{nS}, g_{\mathrm{h}}=40 \mathrm{nS}\right)$.

\section{Compensation can produce a variety of target behaviors}

For the purposes of the following analysis, we are using the term "compensation" to denote those conductance parameters that allow each cell to participate in a network with a defined target behavior, regardless of its intrinsic properties. This meaning of compensation does not imply any underlying changes in the neuron's own excitability induced by the formation of the network.

For each cell type we chose a specific target circuit behavior that was represented in most if not all of the experiments with that neuron. Figure 7 shows these for the PD, GM, and DG neurons. Figure $7 A$ shows recordings from each of the neuron classes in the uncoupled state. Figure $7 B$ shows three examples of the target activity for each cell type. The target activity behavior for the PD neurons was alternating bursts between 0.35 and $0.5 \mathrm{~Hz}$, with an autocorrelation of $>0.75$ and a slow-wave amplitude of $>5 \mathrm{mV}$. Figure $7 C$ shows the parameter values from nine different $\mathrm{PD}$ neurons that gave this target activity pattern. Note that these compensating values varied twofold to threefold.

The target network activity for the GM neurons was bursts between 0.2 and $0.35 \mathrm{~Hz}$ with an average of one spike per burst, as is shown for three different preparations in Figure $7 B$. This behavior was found in $14 \mathrm{GM}$ neurons taken from 9 preparations. The parameters that gave rise to these similar target network behaviors are shown in Figure 7C.

The DG neuron is part of the gastric mill rhythm, often fires long slow bursts during gastric mill activity, and is therefore likely to have membrane currents consistent with slower bursting dynamics. When coupled to the Morris-Lecar model neuron, the DG neuron often formed an activity pattern in which multiple model neuron bursts alternated with a longer DG neuron burst (Fig. 7C). Therefore, we treated this as the target activity pattern for the DG neuron, and Figure 7C shows the $g_{\text {syn }}-g_{\mathrm{h}}$ map locations for 12/12 DG neurons that produced the same target activity pattern.

Figures 5 and 7 show that it was possible to get the same target output out of every LP cell (or DG, GM, or PD) at some value of $\mathrm{g}_{\text {syn }}$ and $\mathrm{g}_{\mathrm{h}}$. In contrast, if we chose one fixed $g_{\text {syn }}-g_{\mathrm{h}}$ parameter set, we saw diverse outputs from cells of the same type. Figure 8 shows the $g_{\text {syn }}-g_{\mathrm{h}}$ parameter sets and accompanying voltage recordings of some of the neurons from Figures 5 and 7. LP \#1 and LP \#3 were bursting, although with different frequencies, duty cycles, spikes per burst, and spike frequencies. LP \#2 was tonically spiking. The same diversity of output from the PD, GM, and DG neurons seen in Figure 7 is also exhibited by the other cell types. Thus, these diverse neurons can produce equivalent outputs if one tunes $g_{\text {syn }}$ and $g_{\mathrm{h}}$ to compensate for differences in neuronal intrinsic excitability. If instead we arbitrarily select one $g_{\text {syn }}$ value and one $g_{\mathrm{h}}$ value, not surprisingly the underlying excitability differences will produce a variety of outputs at identical map locations.

\section{Relationships between intrinsic properties and network behavior}

We wanted to determine whether there were any relationships between the intrinsic membrane properties measured in the isolated neurons and the activity of those neurons in the network formed with the model Morris-Lecar neuron. For all instances of half-center activity in an experiment, we averaged the following properties for all half-center networks: the number of spikes per burst, spike frequency within each burst, duty cycle (the ratio of the burst duration to the period of the oscillation), slow-wave amplitude, autocorrelation score, and $g_{\mathrm{h}}$. Additionally, for each map we calculated the fraction of the map showing half-center activity and the standard deviation of $g_{\mathrm{h}}$. 
Table 2 shows the correlations between each of the intrinsic properties and eight different measures of network performance using pooled data for all of the cell types. Only 9 of the possible 48 correlations were statistically significant after correction for multiple comparisons. The two strongest correlations are shown in detail in Figure 9. The relationship between spike threshold and the mean $g_{\mathrm{h}}$ of the half-center networks is shown in Figure $9 A$. The top plot shows all four cell types fit with a single regression line. This shows that more depolarized values of spike threshold are associated with halfcenters found at lower values of $g_{\mathrm{h}}$. The four bottom plots of Figure $9 A$ show each of the cell types individually. The GM and LP neurons showed significant correlations between spike threshold and mean $g_{\mathrm{h}}$, while the PD and DG neurons did not.

Figure $9 B$ shows the relationship between the spike rate at $+1 \mathrm{nA}$ and the mean number of spikes per burst. When all of the cell types are pooled there is a strong positive correlation seen, and this correlation is preserved in the DG and LP neurons, but not in the GM and PD neurons.

\section{Discussion}

Appropriate animal behavior demands that the neural circuits responsible be adequately tuned for the performance of those behaviors. It is therefore often assumed that appropriate circuit behavior requires that every cellular and synaptic property that underlies those behaviors be tightly regulated. In this article we provide a simple set of experiments demonstrating that the parameters necessary for extrinsically imposed artificial conductances to produce tightly constrained circuit performance are as variable as the measures of intrinsic properties of the neurons.

\section{Biological compensation}

Compensation is now understood to be an important part of the ongoing processes that maintain stable circuit function under many conditions, both normal and pathological. Compensation during development undoubtedly accounts for the numerous instances of knock-outs of important channel and receptor genes with little or no adult phenotype (Hodges et al., 2009), and can result in little obvious effect of overexpression of channel genes (MacLean et al., 2003, 2005), even in instances when acute pharmacological manipulations of the same channels produce substantial physiological effects (Swensen and Bean, 2005). However, in most cases where compensation is invoked to explain the lack of a phenotype, it is usually not known what changes in channels or receptors account for the compensation. Even in those cases in which a change in expression of one gene is correlated with the expression in
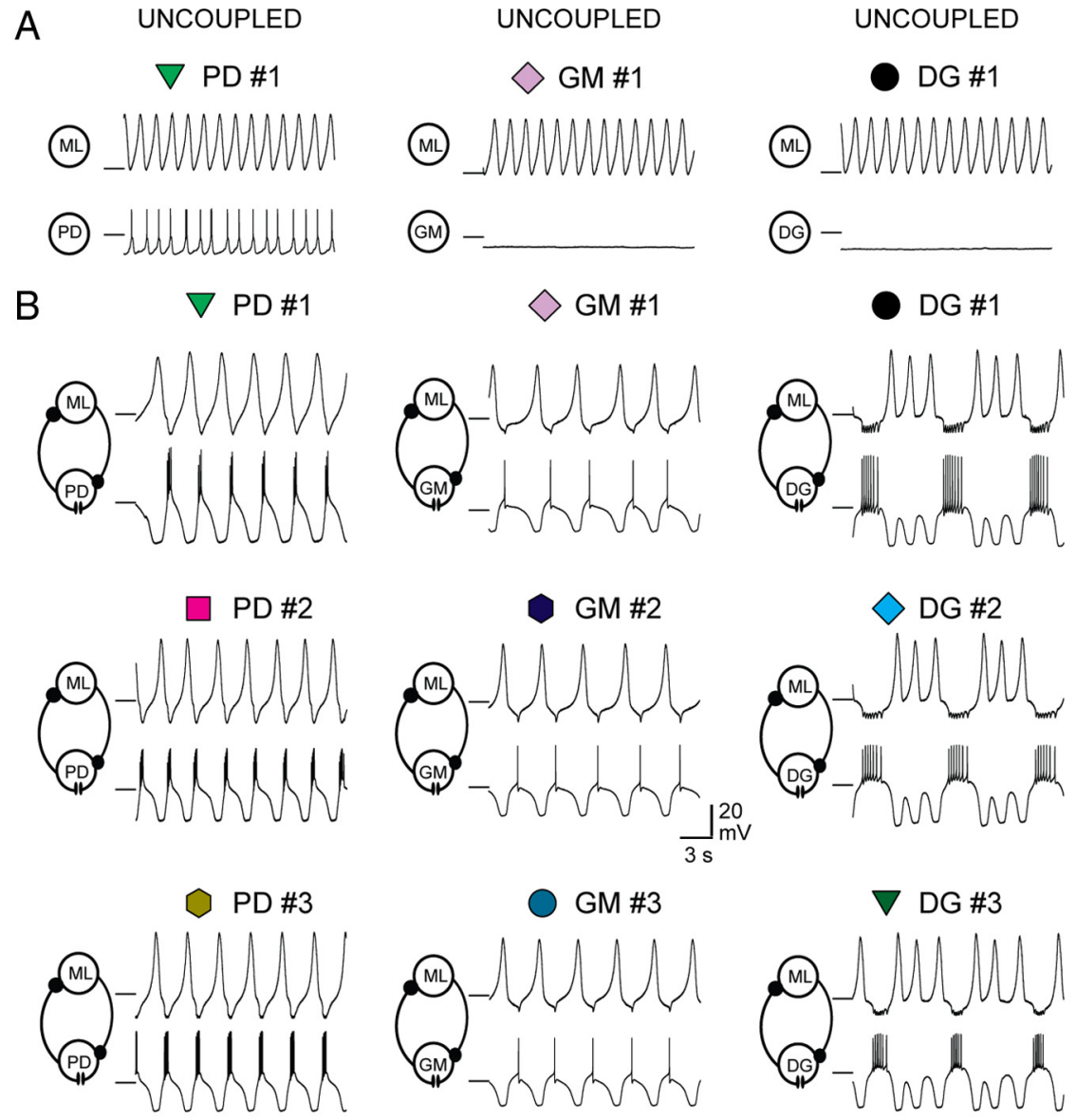

DG \#3

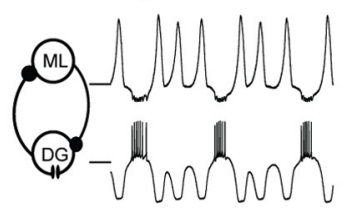

$-50 \mathrm{mV}$
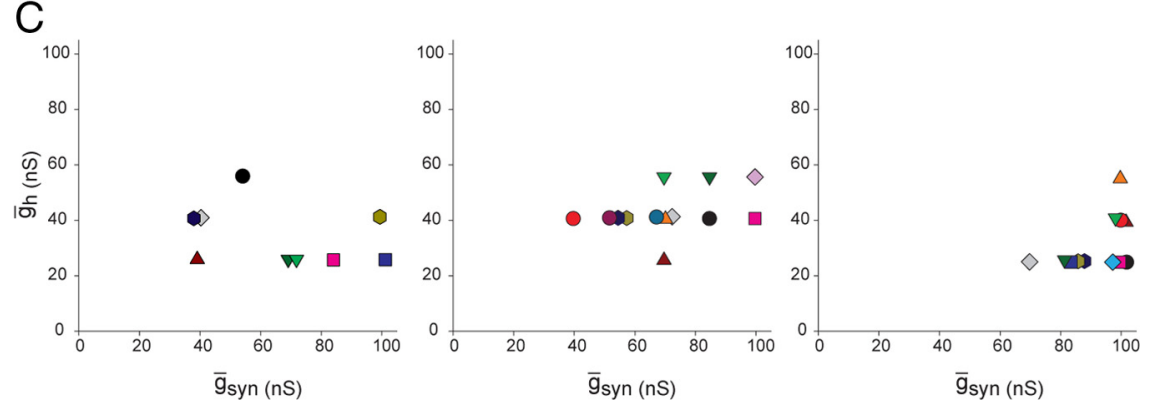

Figure 7. Similar behavior can be elicited from intrinsically variable $P D, G M$, or DG neurons using two artificial conductances. $A$, Voltage traces for uncoupled networks built from a Morris-Lecar neuron and a PD, GM, or DG neuron. $B$, Voltage traces from three PD neurons (first column), three GM neurons (middle column), or three DG neurons (third column) showing similar outputs with different values of $g_{\text {syn }}$ and $g_{\mathrm{h}}$, as shown in C (symbols correspond to those in Fig. 3). C, $g_{\text {syn }}-g_{\mathrm{h}}$ parameter combinations that produced similar outputs shown in $\boldsymbol{B}$.

another (MacLean et al., 2003, 2005), it may not be clear whether the reported change is one of many compensating changes or whether it alone is sufficient to account for the phenotype.

Unlike the compensatory changes that are seen during development or after overexpression experiments in which the neurons themselves change the values of one or more of their conductances to respond to the perturbation, we are making an acute measurement of the parameters that can achieve a shortterm compensation for the variability in intrinsic properties of the neurons. In a sense, these acute measurements are a read-out of which changes could, in principle, achieve longer-term biological compensation. In the context of this article, there were no changes in the neurons' own excitability during the experiments 
A
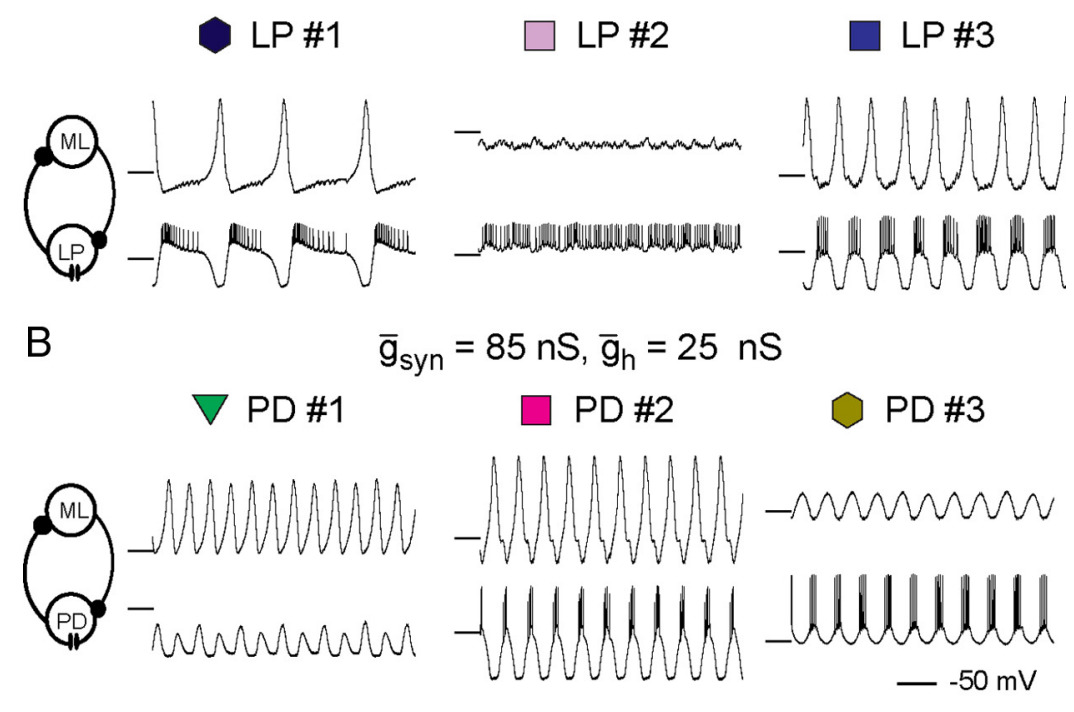

C $\overline{\mathrm{g}}_{\mathrm{syn}}=55 \mathrm{nS}, \overline{\mathrm{g}}_{\mathrm{h}}=55 \mathrm{nS}$ GM \#1 - GM\#2

GM \#3

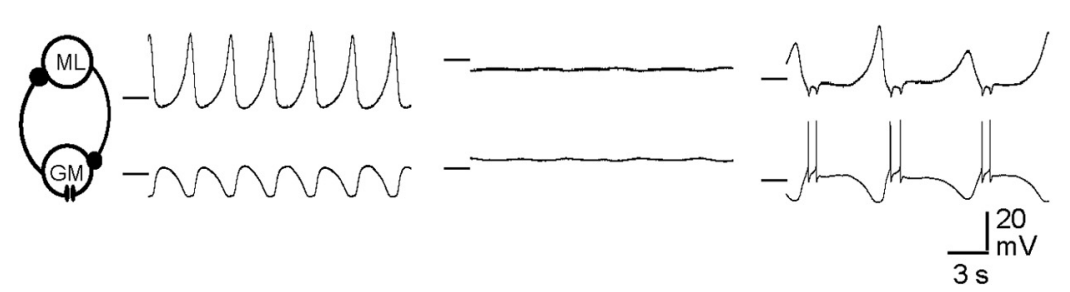

D $\quad \overline{\mathrm{g}}_{\mathrm{syn}}=10 \mathrm{nS}, \overline{\mathrm{g}}_{\mathrm{h}}=25 \mathrm{nS}$

- DG \#1 $>D G \# 2$ $\nabla D G \# 3$

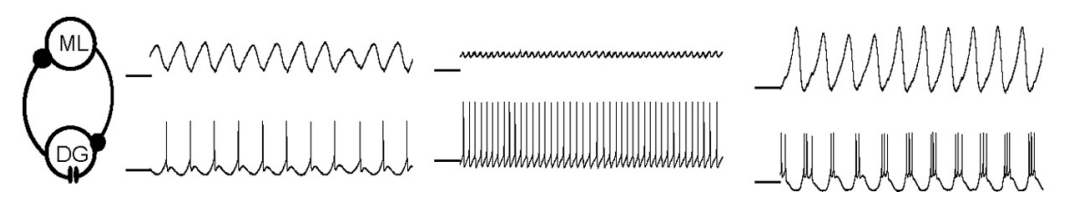

Figure 8. Diverse outputs result from intrinsically variable neurons at single $g_{\text {syn }}-g_{\mathrm{h}}$ parameter value combinations. $\boldsymbol{A}$, Voltage traces from three $L P$ neurons at a single $g_{\text {syn }}-g_{\mathrm{h}}$ map location. $\boldsymbol{B}-\boldsymbol{D}$, Same as $\boldsymbol{A}$, except for PD, GM, and DG, respectively.

rations (Prescott and De Koninck, 2002; Cudmore and Turrigiano, 2004; Alaburda et al., 2005; Dougherty et al., 2005; Idoux et al., 2006; Sautois et al., 2007; Helmstaedter et al., 2009), with the implicit hope that these electrophysiological measures are directly predictive of a cell's activity within a circuit (Gittis and du Lac, 2007; Otte et al., 2010). Our data come from neurons that are uniquely identifiable on the basis of their anatomical projections (Maynard and Dando, 1974). Although the mean values of some of the intrinsic properties are statistically different across cell types (Table 1), the overlap of the individual cells' measurements would preclude these values on their own as being reliable indications of neuronal identity. A number of studies have argued for additional classification schemes based on measures such as gene expression profiles (Kamme et al., 2003; Nelson et al., 2006; Sugino et al., 2006), morphology (Kriegstein and Dichter, 1983; Nimchinsky et al., 1999; Prescott and De Koninck, 2002; Yasaka et al., 2007), neurotransmitter complement (Lints and Emmons, 1999; Maccaferri and Lacaille, 2003), or combinations of the above (Markram et al., 2004; Butt et al., 2005; Dougherty et al., 2005; Sautois et al., 2007). Work continues to determine which measures of neuronal identity are most reliable for neurons in large and complex circuits.

The initial premise of this study was to determine whether a functional assay, such as that used here, might provide a superior measure of neuronal excitability compared with traditional measures of intrinsic properties, because it would measure voltage responses in a more dynamic and relevant way than traditional measures of intrinsic excitability. Visual inspection of the pooled maps of the different cell types (Figs. 5A, 6) shows clear evidence of cell-specific structures.

as assayed by repeat measures of the same map locations over the course of the experiment.

Because the compensating changes were produced using the dynamic clamp in our study, it is unambiguous that these compensations are sufficient to produce the target circuit performance. Our work shows that similar outputs can be elicited from variable neurons using only two conductances. Nonetheless, in actual biological circuits we imagine that a variety of compensatory changes at multiple loci within a circuit might account for apparently unchanged behavioral function. Biological neurons in dynamic circuits have many more conductances, producing innumerable parameter combinations to maintain appropriately nuanced electrical phenotypes.

The utility of intrinsic properties to classify neuronal cell type Intrinsic properties, such as those measured here, are commonly used to describe and classify neurons in a wide variety of prepa-
Nonetheless, there is enough overlap in these maps so that the individual maps from neurons of different cell types will not necessarily be diagnostic of that neuron's identity, using this particular Morris-Lecar model neuron and these parameter ranges. These results suggest that it might be possible to create a better functional assay using different model neurons or by adding an additional voltage-dependent current, because even two-cell, half-center oscillators show qualitatively different behavior depending on their intrinsic currents (Daun et al., 2009). Thus, a fuller exploration of different model neurons might find ones that would more reliably separate neurons by cell type by exploring the full set of dynamics in each neuronal type.

\section{From intrinsic properties to circuit performance and back}

Circuit dynamics result from complex and nonlinear relationships between synaptic strength and the intrinsic properties of the 
Table 2. Correlations between intrinsic membrane properties and network properties

\begin{tabular}{|c|c|c|c|c|c|c|}
\hline Network property & Input resistance & Spike threshold & Fl slope & Spike frequency at $+1 \mathrm{nA}$ & $\begin{array}{l}\text { Minimum resting } \\
\text { voltage }\end{array}$ & Spike height \\
\hline Mean spikes per burst & NS & $p<0.001 R^{2}=0.40$ & NS & $p<0.001 R^{2}=0.65$ & $p<0.01 R^{2}=0.26$ & NS \\
\hline Mean burst spike frequency & NS & NS & NS & NS & NS & NS \\
\hline Mean duty cycle & NS & NS & NS & NS & NS & NS \\
\hline Mean slow wave amplitude & $p<0.01 R^{2}=0.26$ & NS & NS & NS & NS & NS \\
\hline Mean autocorrelation & NS & $p<0.01 R^{2}=0.30$ & NS & NS & $p<0.001 R^{2}=0.36$ & NS \\
\hline Mean $g_{\mathrm{h}}$ & NS & $p<0.001 R^{2}=0.45$ & NS & $p<0.001 R^{2}=0.36$ & $p<0.001 R^{2}=0.41$ & NS \\
\hline Fraction of half-centers & NS & NS & NS & NS & NS & NS \\
\hline Standard deviation of $g_{\mathrm{h}}$ & NS & NS & NS & NS & NS & NS \\
\hline
\end{tabular}

Pairwise correlations were measured for each network property and each intrinsic property; $p$ values were determined using the Pearson correlation test. All cell types have been pooled. For all correlations with a significant $p$ value $(p<0.05)$, $p$ value and $R^{2}$ are shown. Correlations that were not significant have been labeled NS. The $p$ values have been adjusted using the Holm-Bonferroni correction for multiple comparisons.

A Spike threshold vs. mean $\mathbf{g}_{h}$
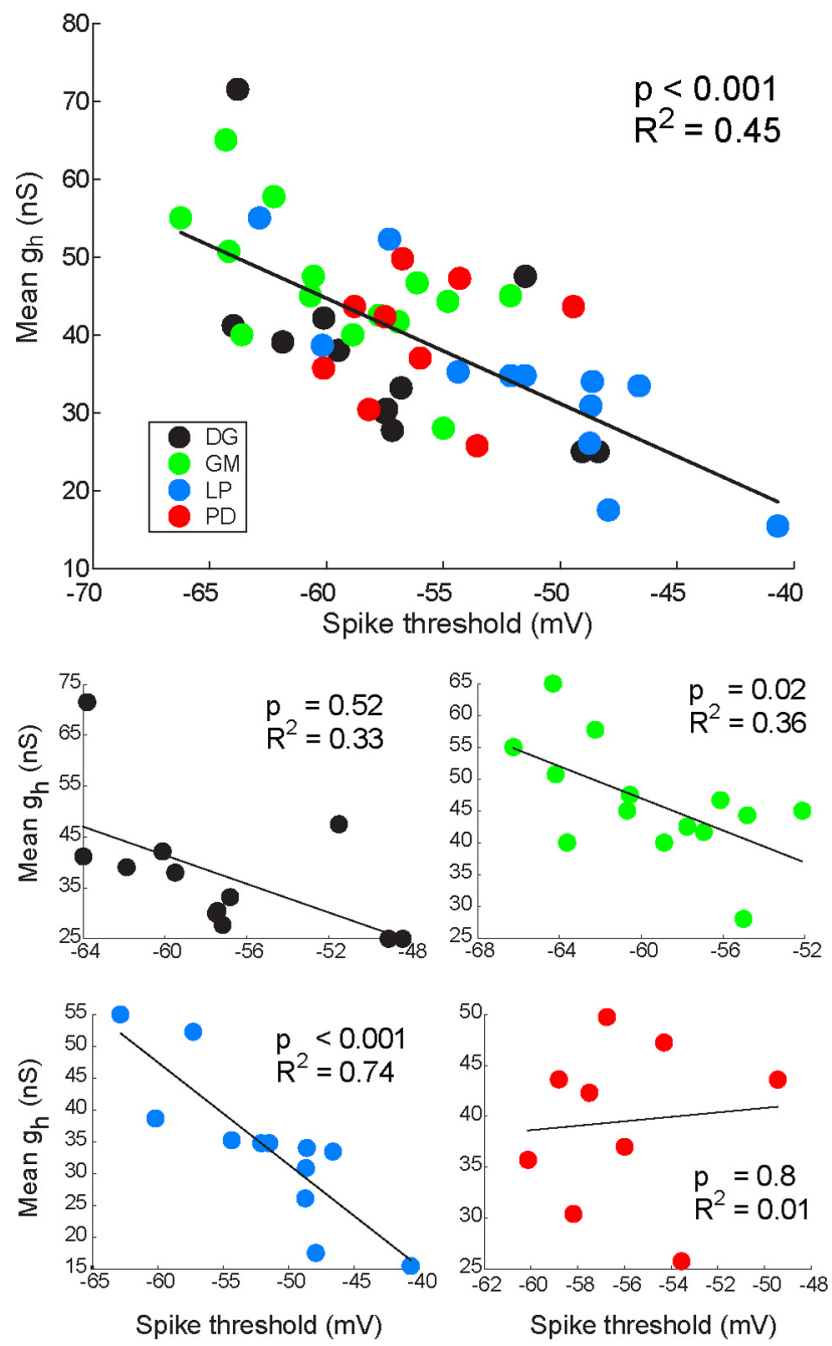

B

+1 nA spike rate vs mean number of spikes per burst
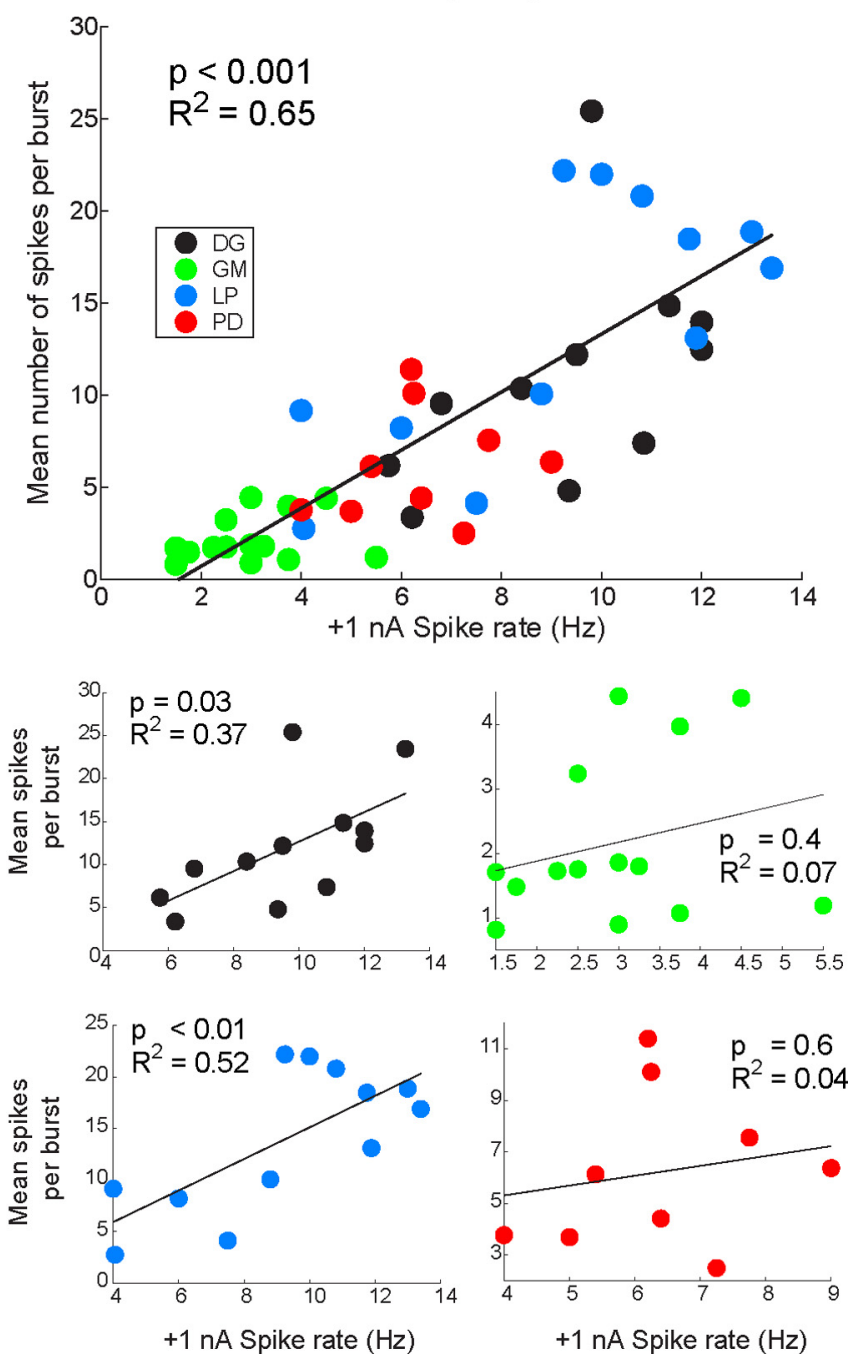

Figure 9. Correlations between intrinsic property measurements and features of the hybrid circuit half-center activity. $\boldsymbol{A}$, The relationship between spike threshold and mean $g_{\mathrm{h}}$. Top plot shows data from all neurons $(n=47)$ plotted together and the bottom four plots show each of the neuron classes separately plotted. Color code shows cell types. $\boldsymbol{B}$, The relationship between the spike rate at $+1 \mathrm{nA}$ and the mean number of spikes per burst. Top plot shows all neurons pooled and bottom four plots are neurons separated by cell type.

neurons in the network. One of the challenges in understanding circuit behavior is to determine the extent to which each conductance contributes to circuit performance. When intrinsic properties are measured, the assumption is often made that measures such as input resistance, FI curve, or spike threshold will be accurate predictors of how that neuron will perform in a network. In some cases it is relatively easy to relate a change in the strength of a synapse or the maximal conductance of one membrane current to circuit behavior (Sharp et al., 1996). Table 2 shows that in this study there are fewer significant correlations between the measurements of intrinsic properties and network performance than might have been expected. Nonetheless, there are two features of this study that make it easy to understand why simple intuition might fail for many of these relationships. First, the 
networks we created here are asymmetric, so that the two neurons, model and biological, have quite different properties. Second, and perhaps most importantly, the Morris-Lecar model neuron is a strong oscillator, and its nonlinearities can make it very difficult to predict simply the behavior of a closed loop circuit in which one side is a strong oscillator and the other is a different kind of neuron with very different intrinsic properties (Kopell et al., 1998).

\section{Compensation and homeostasis}

There is an ever-growing body of literature that suggests that the activity levels of individual neurons and networks are homeostatically regulated to maintain a physiologically appropriate and stable network performance in the face of growth, channel turnover, and perturbations by modification of either synaptic or intrinsic parameters or both (LeMasson et al., 1993; Turrigiano et al., 1994; Liu et al., 1998; Golowasch et al., 1999a; Turrigiano and Nelson, 2000, 2004; Paradis et al., 2001; Soto-Trevino et al., 2001; Luther et al., 2003; Davis, 2006; Haedo and Golowasch, 2006; Pratt and Aizenman, 2007; Rich and Wenner, 2007; Turrigiano, 2007, 2008; Zhang and Golowasch, 2007; Wilhelm and Wenner, 2008; Dickman and Davis, 2009; Frank et al., 2009; Wilhelm et al., 2009; Zhang et al., 2009; Gunay and Prinz, 2010; O’Leary et al., 2010; Olypher and Prinz, 2010).

Implicit in the concept of homeostasis is that there is a target or desired phenotype or activity pattern and some kind of sensor(s) that detect deviations from that target level. These "error signals" are then used to trigger alterations of one or more processes to bring the system back to its target activity pattern. While the compensation we measure here is not a result of biological homeostatic tuning, it is interesting that the range of values that were necessary to apply to variable neurons to recover a target network activity is similar to the range of many biological parameters that were measured across individuals (Golowasch et al., 1999b; Schulz et al., 2006, 2007; Goaillard et al., 2009). That said, it is important to remember that some ion channel mutants have striking phenotypes, as even homeostatically regulating systems cannot compensate for the loss of some functions (Liu et al., 1998) or the gain of others. Consequently, one of the challenges for the future will be to uncover potential molecular mechanisms that favor compensation (MacLean et al., 2003; MacLean et al., 2005) and/or coregulation of ion channels (Gittis and du Lac, 2007; Schulz et al., 2007; Tobin et al., 2009).

\section{References}

Achard P, De Schutter E (2006) Complex parameter landscape for a complex neuron model. PLoS Comput Biol 2:e94.

Alaburda A, Russo R, MacAulay N, Hounsgaard J (2005) Periodic highconductance states in spinal neurons during scratch-like network activity in adult turtles. J Neurosci 25:6316-6321.

Buchholtz F, Golowasch J, Epstein IR, Marder E (1992) Mathematical model of an identified stomatogastric ganglion neuron. J Neurophysiol 67:332-340.

Butt SJ, Lundfald L, Kiehn O (2005) EphA4 defines a class of excitatory locomotor-related interneurons. Proc Natl Acad Sci U S A 102:14098-14103.

Clemens S, Massabuau JC, Legeay A, Meyrand P, Simmers J (1998) In vivo modulation of interacting central pattern generators in lobster stomatogastric ganglion: influence of feeding and partial pressure of oxygen. J Neurosci 18:2788-2799.

Cudmore RH, Turrigiano GG (2004) Long-term potentiation of intrinsic excitability in LV visual cortical neurons. J Neurophysiol 92:341-348.

Daun S, Rubin JE, Rybak IA (2009) Control of oscillation periods and phase durations in half-center central pattern generators: a comparative mechanistic analysis. J Comput Neurosci 27:3-36.

Davis GW (2006) Homeostatic control of neural activity: from phenomenology to molecular design. Annu Rev Neurosci 29:307-323.
Dickman DK, Davis GW (2009) The schizophrenia susceptibility gene dysbindin controls synaptic homeostasis. Science 326:1127-1130.

Dorval AD, Christini DJ, White JA (2001) Real-time linux dynamic clamp: a fast and flexible way to construct virtual ion channels in living cells. Ann Biomed Eng 29:897-907.

Dougherty KJ, Sawchuk MA, Hochman S (2005) Properties of mouse spinal lamina I GABAergic interneurons. J Neurophysiol 94:3221-3227.

Frank CA, Pielage J, Davis GW (2009) A presynaptic homeostatic signaling system composed of the Eph receptor, ephexin, $\mathrm{Cdc} 42$, and CaV2.1 calcium channels. Neuron 61:556-569.

Gittis AH, du Lac S (2007) Firing properties of GABAergic versus nonGABAergic vestibular nucleus neurons conferred by a differential balance of potassium currents. J Neurophysiol 97:3986-3996.

Goaillard JM, Taylor AL, Schulz DJ, Marder E (2009) Functional consequences of animal-to-animal variation in circuit parameters. Nat Neurosci 12:1424-1430.

Goldman MS, Golowasch J, Marder E, Abbott LF (2001) Global structure, robustness, and modulation of neuronal models. J Neurosci 21:5229-5238.

Golowasch J, Buchholtz F, Epstein IR, Marder E (1992) Contribution of individual ionic currents to activity of a model stomatogastric ganglion neuron. J Neurophysiol 67:341-349.

Golowasch J, Casey M, Abbott LF, Marder E (1999a) Network stability from activity-dependent regulation of neuronal conductances. Neural Comput 11:1079-1096.

Golowasch J, Abbott LF, Marder E (1999b) Activity-dependent regulation of potassium currents in an identified neuron of the stomatogastric ganglion of the crab Cancer borealis. J Neurosci 19:RC33:1-5.

Golowasch J, Goldman MS, Abbott LF, Marder E (2002) Failure of averaging in the construction of a conductance-based neuron model. J Neurophysiol 87:1129-1131.

Gunay C, Prinz AA (2010) Model calcium sensors for network homeostasis: sensor and readout parameter analysis from a database of model neuronal networks. J Neurosci 30:1686-1698.

Haedo RJ, Golowasch J (2006) Ionic mechanism underlying recovery of rhythmic activity in adult isolated neurons. J Neurophysiol 96:18601876.

Helmstaedter M, Sakmann B, Feldmeyer D (2009) L2/3 interneuron groups defined by multiparameter analysis of axonal projection, dendritic geometry, and electrical excitability. Cereb Cortex 19:951-962.

Hodges MR, Wehner M, Aungst J, Smith JC, Richerson GB (2009) Transgenic mice lacking serotonin neurons have severe apnea and high mortality during development. J Neurosci 29:10341-10349.

Hooper SL, O’Neil MB, Wagner RJ, Ewer J, Golowasch J, Marder E (1986) The innervation of the pyloric region of the crab, Cancer borealis: homologous muscles in decapod species are differently innervated. J Comp Physiol A Neuroethol Sens Neural Behav Physiol 159:227-240.

Idoux E, Serafin M, Fort P, Vidal PP, Beraneck M, Vibert N, Muhlethaler M, Moore LE (2006) Oscillatory and intrinsic membrane properties of guinea pig nucleus prepositus hypoglossi neurons in vitro. J Neurophysiol 96:175-196.

Kamme F, Salunga R, Yu J, Tran DT, Zhu J, Luo L, Bittner A, Guo HQ, Miller N, Wan J, Erlander M (2003) Single-cell microarray analysis in hippocampus CA1: demonstration and validation of cellular heterogeneity. J Neurosci 23:3607-3615.

Kiehn O, Harris-Warrick RM (1992a) Serotonergic stretch receptors induce plateau properties in a crustacean motor neuron by a dual-conductance mechanism. J Neurophysiol 68:485-495.

Kiehn O, Harris-Warrick RM (1992b) 5-HT modulation of hyperpolarizationactivated inward current and calcium-dependent outward current in a crustacean motor neuron. J Neurophysiol 68:496-508.

Kilman VL, Marder E (1996) Ultrastructure of the stomatogastric ganglion neuropil of the crab, Cancer borealis. J Comp Neurol 374:362-375.

Kopell N, Abbott LF, Soto-Trevino C (1998) On the behavior of a neural oscillator electrically coupled to a bistable element. Physica D 121:367-395.

Kriegstein AR, Dichter MA (1983) Morphological classification of rat cortical neurons in cell culture. J Neurosci 3:1634-1647.

LeMasson G, Marder E, Abbott LF (1993) Activity-dependent regulation of conductances in model neurons. Science 259:1915-1917.

Lints R, Emmons SW (1999) Patterning of dopaminergic neurotransmitter identity among Caenorhabditis elegans ray sensory neurons by a TGF $\beta$ family signaling pathway and a Hox gene. Development 126:5819-5831. 
Liu Z, Golowasch J, Marder E, Abbott LF (1998) A model neuron with activity-dependent conductances regulated by multiple calcium sensors. J Neurosci 18:2309-2320.

Luther JA, Robie AA, Yarotsky J, Reina C, Marder E, Golowasch J (2003) Episodic bouts of activity accompany recovery of rhythmic output by a neuromodulator- and activity-deprived adult neural network. J Neurophysiol 90:2720-2730.

Maccaferri G, Lacaille JC (2003) Interneuron diversity series: hippocampal interneuron classifications-making things as simple as possible, not simpler. Trends Neurosci 26:564-571.

MacLean JN, Zhang Y, Johnson BR, Harris-Warrick RM (2003) Activityindependent homeostasis in rhythmically active neurons. Neuron 37:109-120.

MacLean JN, Zhang Y, Goeritz ML, Casey R, Oliva R, Guckenheimer J, Harris-Warrick RM (2005) Activity-independent coregulation of $\mathrm{I}_{\mathrm{A}}$ and $I_{h}$ in rhythmically active neurons. J Neurophysiol 94:3601-3617.

Marder E, Bucher D (2007) Understanding circuit dynamics using the stomatogastric nervous system of lobsters and crabs. Annu Rev Physiol 69:291-316.

Marder E, Eisen JS (1984) Transmitter identification of pyloric neurons: electrically coupled neurons use different neurotransmitters. J Neurophysiol 51:1345-1361.

Markram H, Toledo-Rodriguez M, Wang Y, Gupta A, Silberberg G, Wu C (2004) Interneurons of the neocortical inhibitory system. Nat Rev Neurosci 5:793-807.

Maynard DM, Dando MR (1974) The structure of the stomatogastric neuromuscular system in Callinectes sapidus, Homarus americanus and Panulirus argus (decapoda crustacea). Philos Trans R Soc Lond B Biol Sci 268:161-220.

Morris C, Lecar H (1981) Voltage oscillations in the barnacle giant muscle fiber. Biophys J 35:193-213.

Nelson SB, Sugino K, Hempel CM (2006) The problem of neuronal cell types: a physiological genomics approach. Trends Neurosci 29:339-345.

Nimchinsky EA, Gilissen E, Allman JM, Perl DP, Erwin JM, Hof PR (1999) A neuronal morphologic type unique to humans and great apes. Proc Natl Acad Sci U S A 96:5268-5273.

Nusbaum MP, Beenhakker MP (2002) A small-systems approach to motor pattern generation. Nature 417:343-350.

O’Leary T, van Rossum MC, Wyllie DJ (2010) Homeostasis of intrinsic excitability in hippocampal neurones: dynamics and mechanism of the response to chronic depolarization. J Physiol 588:157-170.

Olypher AV, Prinz AA (2010) Geometry and dynamics of activitydependent homeostatic regulation in neurons. J Comput Neurosci 28:361-374.

Olypher A, Cymbalyuk G, Calabrese RL (2006) Hybrid systems analysis of the control of burst duration by low-voltage-activated calcium current in leech heart interneurons. J Neurophysiol 96:2857-2867.

Otte S, Hasenstaub A, Callaway EM (2010) Cell type-specific control of neuronal responsiveness by gamma-band oscillatory inhibition. J Neurosci 30:2150-2159.

Paradis S, Sweeney ST, Davis GW (2001) Homeostatic control of presynaptic release is triggered by postsynaptic membrane depolarization. Neuron 30:737-749.

Pratt KG, Aizenman CD (2007) Homeostatic regulation of intrinsic excitability and synaptic transmission in a developing visual circuit. J Neurosci 27:8268-8277.

Prescott SA, De Koninck Y (2002) Four cell types with distinctive membrane properties and morphologies in lamina I of the spinal dorsal horn of the adult rat. J Physiol 539:817-836.

Prinz AA, Bucher D, Marder E (2004) Similar network activity from disparate circuit parameters. Nat Neurosci 7:1345-1352.

Rich MM, Wenner P (2007) Sensing and expressing homeostatic synaptic plasticity. Trends Neurosci 30:119-125.

Sautois B, Soffe SR, Li WC, Roberts A (2007) Role of type-specific neuron properties in a spinal cord motor network. J Comput Neurosci 23:59-77.

Schulz DJ, Goaillard JM, Marder E (2006) Variable channel expression in identified single and electrically coupled neurons in different animals. Nat Neurosci 9:356-362.

Schulz DJ, Goaillard JM, Marder EE (2007) Quantitative expression profil- ing of identified neurons reveals cell-specific constraints on highly variable levels of gene expression. Proc Natl Acad Sci U S A 104:13187-13191.

Selverston AI, Russell DF, Miller JP, King DG (1976) The stomatogastric nervous system: structure and function of a small neural network. Prog Neurobiol 7:215-290.

Sharp AA, O’Neil MB, Abbott LF, Marder E (1993) Dynamic clamp: computer-generated conductances in real neurons. J Neurophysiol 69:992-995

Sharp AA, Skinner FK, Marder E (1996) Mechanisms of oscillation in dynamic clamp constructed two-cell half-center circuits. J Neurophysiol 76:867-883.

Sobie EA (2009) Parameter sensitivity analysis in electrophysiological models using multivariable regression. Biophys J 96:1264-1274.

Sorensen M, DeWeerth S, Cymbalyuk G, Calabrese RL (2004) Using a hybrid neural system to reveal regulation of neuronal network activity by an intrinsic current. J Neurosci 24:5427-5438.

Soto-Trevino C, Thoroughman KA, Marder E, Abbott LF (2001) Activitydependent modification of inhibitory synapses in models of rhythmic neural networks. Nat Neurosci 4:297-303.

Sugino K, Hempel CM, Miller MN, Hattox AM, Shapiro P, Wu C, Huang ZJ Nelson SB (2006) Molecular taxonomy of major neuronal classes in the adult mouse forebrain. Nat Neurosci 9:99-107.

Swensen AM, Bean BP (2005) Robustness of burst firing in dissociated Purkinje neurons with acute or long-term reductions in sodium conductance. J Neurosci 25:3509-3520.

Taylor AL, Goaillard JM, Marder E (2009) How multiple conductances determine electrophysiological properties in a multicompartment model J Neurosci 29:5573-5586.

Tobin AE, Calabrese RL (2006) Endogenous and half-center bursting in morphologically inspired models of leech heart interneurons. J Neurophysiol 96:2089-2106.

Tobin AE, Cruz-Bermudez ND, Marder E, Schulz DJ (2009) Correlations in ion channel mRNA in rhythmically active neurons. PLoS One 4:e6742.

Turrigiano G (2007) Homeostatic signaling: the positive side of negative feedback. Curr Opin Neurobiol 17:318-324

Turrigiano GG (2008) The self-tuning neuron: synaptic scaling of excitatory synapses. Cell 135:422-435.

Turrigiano GG, Nelson SB (2000) Hebb and homeostasis in neuronal plasticity. Curr Opin Neurobiol 10:358-364.

Turrigiano GG, Nelson SB (2004) Homeostatic plasticity in the developing nervous system. Nat Rev Neurosci 5:97-107.

Turrigiano G, Abbott LF, Marder E (1994) Activity-dependent changes in the intrinsic properties of cultured neurons. Science 264:974-977.

Weimann JM, Meyrand P, Marder E (1991) Neurons that form multiple pattern generators: identification and multiple activity patterns of gastric/ pyloric neurons in the crab stomatogastric system. J Neurophysiol 65:111-122.

Wilhelm JC, Wenner P (2008) GABA transmission is a critical step in the process of triggering homeostatic increases in quantal amplitude. Proc Natl Acad Sci U S A 105:11412-11417.

Wilhelm JC, Rich MM, Wenner P (2009) Compensatory changes in cellular excitability, not synaptic scaling, contribute to homeostatic recovery of embryonic network activity. Proc Natl Acad Sci U S A 106:6760-6765.

Yasaka T, Kato G, Furue H, Rashid MH, Sonohata M, Tamae A, Murata Y, Masuko S, Yoshimura M (2007) Cell-type-specific excitatory and inhibitory circuits involving primary afferents in the substantia gelatinosa of the rat spinal dorsal horn in vitro. J Physiol 581:603-618.

Zhang B, Harris-Warrick RM (1995) Calcium-dependent plateau potentials in a crab stomatogastric ganglion motor neuron. I. Calcium curren and its modulation by serotonin. J Neurophysiol 74:1929-1937.

Zhang B, Wootton JF, Harris-Warrick RM (1995) Calcium-dependent plateau potentials in a crab stomatogastric ganglion motor neuron. II Calcium-activated slow inward current. J Neurophysiol 74:1938-1946.

Zhang Y, Golowasch J (2007) Modeling recovery of rhythmic activity: hypothesis for the role of a calcium pump. Neurocomputing 70:1657-1662.

Zhang Y, Khorkova O, Rodriguez R, Golowasch J (2009) Activity and neuromodulatory input contribute to the recovery of rhythmic output after decentralization in a central pattern generator. J Neurophysiol 101:372386 . 